\title{
O ensino de ciências no projeto "um computador por aluno" em escolas públicas de Rondônia
}

The science teaching in in the OLPC project (One Laptop per Child) in public schools in Rondônia, Brazil

Daniele Braga Brasil ${ }^{1}$, Josemar Farias da Silva ${ }^{2}$ e Elizabeth A. L. de Moraes Martines ${ }^{3}$

\section{Resumo}

Em tempos de acirrado desenvolvimento tecnológico, em que computadores ligados à Internet ocupam espaço privilegiado nas ações e nas relações humanas, a escola não pode e não deve se posicionar à margem do processo. Vários autores apontam questões relacionadas à utilização de computadores portáteis por professores e alunos em escolas de vários países, criando um novo campo de estudos. No Brasil está ocorrendo o Projeto UCA (Um Computador por Aluno) e em Rondônia oito escolas públicas tiveram este projeto implantado em 2010 e seus professores vêm se capacitando para sua utilização em sala de aula. Este artigo se propõe a discutir o processo de implantação deste projeto e sua utilização para o ensino de ciências nessas escolas, com o propósito de que sua compreensão poderá subsidiar ações que visem corrigir distorções, sofisticar o processo e contribuir de fato para a melhoria da educação como um todo no estado de Rondônia e em outros estados. A chegada dos computadores portáteis na escola gerou mudanças que necessitam ser estudadas para que possamos entender as implicações destas nas vidas das pessoas envolvidas na situação da utilização desta nova tecnologia que chega às mãos dos alunos e professores, sendo esta uma situação diferente da que acontecia exclusivamente nos laboratórios de informática das escolas.

Palavras-chave: Um Computador por Aluno, Ensino de Ciências, Políticas Públicas.

\begin{abstract}
In times of fierce technological development, in which Internet connected computers occupy a privileged space in the actions and human relationships, the school can not and should not stand on the sidelines of the process. Several authors point out issues related to the use of laptops by teachers and students in schools in many countries creating a new field of study. Brazil is occurring in the UCA Project (One Laptop per Child) and Rondônia eight public schools had implemented this project in 2010 and their teachers are receiving training to use in the classroom. This article aims to discuss the process of implementation of this project and its use for science teaching in these schools in order that their understanding may support actions aimed at correcting distortions, sophisticate the process and actually contribute to the improvement of education as a whole in the state of Rondônia and other states. The arrival of laptops in school led to changes that need to be studied in order to understand their implications in the lives of the people involved in the situation of using this new technology comes into the hands of students and teachers, this being a different situation that occurred exclusively computer labs in schools.
\end{abstract}

Keywords: One Laptop per Child, Science Education, Public Policy.

\footnotetext{
${ }^{1}$ Professora de Biologia da Rede Pública de Rondônia. Discente do MAPSI/UNIR | bragabrasil.daniele@gmail.com

${ }^{2}$ Discente do MAPSI/UNIR | jfarias80@gmail.com

${ }^{3}$ Docente do MAPSI/UNIR | bethmartines@gmail.com
} 


\section{Introdução}

Este trabalho é resultado parcial de pesquisas que vêm sendo realizadas no contexto da Psicologia Escolar contemporânea, que tem se revisto em suas bases epistemológicas e realizado um conjunto de pesquisas visando à compreensão dos fenômenos e processos escolares e educativos (SOUZA, 2010). Após a década de 80, um conjunto de pesquisas em educação nesta perspectiva, possibilitou compreender o fracasso escolar enquanto resultado de uma complexa rede de relações que envolvem questões institucionais, estruturais, individuais, de funcionamento e também questões políticas que se desenvolvem no dia-a-dia da escola. Outros problemas escolares também estão sendo estudados nesta perspectiva e nosso objeto de estudo neste trabalho é o uso de novas tecnologias no ensino de ciências no âmbito do Projeto Um Computador por Aluno (UCA) em Rondônia.

Considerando que as evoluções socioculturais e tecnológicas geram incessantes mudanças nas organizações, nas comunicações humanas, nas ações e no nosso pensamento, revelando um novo universo no dia-a-dia de crianças, jovens e adultos, é comum a defesa de que é necessário o desenvolvimento de autonomia para a obtenção e a seleção das informações disponíveis, no processo de construção do conhecimento. Papert (1985), Breton (1991), Moran (2000) e Giordan (2008) defendem que, quando ligado em rede, o computador se converte em um meio de comunicação cada dia mais presente na vida de nossos alunos e professores, e a escola se torna um local privilegiado para desenvolver o espírito crítico necessário para lidar com a avalanche informacional com que nos defrontamos no nosso cotidiano.

Este contexto apresenta grande potencial para a aprendizagem, onde o uso de computadores e celulares com acesso à Internet pode contribuir para ampliar as relações humanas, diversificando as possibilidades de interações e diversos estudos referentes à utilização de Novas Tecnologias na Educação estão se constituindo em um novo campo científico, relacionado com o modo como o homem se percebe historicamente constituído e como se encontra inserido na relatividade espaço/tempo, pois, admite-se "[...] as tecnologias como elementos constitutivos e estruturantes do modo de ser, pensar e estar no mundo [...]". (ALMEIDA \& VALENTE, 2011, p. 6).

Assim, neste contexto revolucionário, este trabalho adota a posição defendida por Souza (2010), de que, para se compreender a escola e os problemas de escolarização torna-se necessário pesquisá-la no contexto das políticas públicas educacionais. Nesse sentido, realizar pesquisas sobre as políticas públicas com base na Psicologia Escolar tornase necessário, no sentido de compreender, a partir dos sujeitos que as vivenciam, as questões que precisam ser enfrentadas para se garantir efetivamente uma escola com ensino de qualidade, que não se reflita apenas em números de avaliações externas, mas, que dê um salto qualitativo no sentido de melhoria das relações, com valorização do trabalho docente e, principalmente, que respire democracia e tenha um caráter emancipatório e libertador.

Ao se fazer uma análise histórica, percebemos a escola atravessada por uma série de reformas e de políticas que, geralmente, desconsideram: as especificidades regionais e as necessidades locais; tampouco se discute coletivamente, desprezando os saberes docentes e, muitas vezes, vemos implementadas propostas de cunho compensatório, tentando suprir pretensas carências culturais das classes mais populares. Também não se leva em conta a necessidade de garantir infraestrutura adequada e valorização do profissional para a 
efetivação da mesma, bem como presenciamos paulatinamente a introdução da lógica do mercado na escola, conforme discutido por Ball (2011) ou dentro de uma lógica do gerencialismo, de acordo com Lima e Gandin (2011).

As políticas educacionais implantadas carreiam concepções acerca do público e do privado, do papel do estado, dos fins da educação, da escola enquanto instituição, dos seus professores, gestores, alunos e, a partir dessas concepções, intervêm visando melhorar sua "qualidade", "eficiência". Estas concepções hegemônicas são apropriadas e veiculadas em seus discursos, sem criticidade acerca da lógica em que se assenta e se constrói.

Nosso objetivo é discutir o processo de implantação do Projeto UCA em Rondônia e sua utilização para o ensino de ciências nas oito escolas-piloto com o propósito de que sua compreensão poderá subsidiar ações que visem corrigir distorções, sofisticar o processo, gerar reflexões. Para isto, utilizamos o Ciclo de políticas proposto por Ball, investigando como o Projeto UCA foi gestado, implementado e experimentado, sendo que a preocupação central é a análise da política atentando-se para a sua materialização e consequências, em termos de justiça social, inclusão e equidade. (MAINARDES, 2009).

Para Ball "[...] muitas pesquisas sobre políticas educacionais não têm nenhum sentido de tempo. O aspecto negligenciado mais óbvio é o extravagante a-historicismo" (2011, p. 38). Ainda acerca das políticas educacionais pontua também que "[...] muitas não possuem sentido de "lugar". Não localizam as políticas em algum quadro que ultrapasse o nível nacional nem consegue dar uma explicação analítica ou conduzir a um sentido de localidade nas análises das realizações políticas" (p. 40). Com essas considerações o autor conclui que "o relacionamento nacional/global é outro ponto de mediação no processo de políticas" (p. 40). Ball e Bowe (1992) propõem um modelo para análise de políticas partindo da compreensão de três contextos que se interpenetram: contexto da influência, contexto da produção de texto e contexto da prática. Esses contextos, na visão dos autores, estariam imbricados uns nos outros e não se disporiam de forma linear, não teriam uma dimensão temporal, pois cada um exerceria influência sobre o outro, conforme Figura 1. (MAINARDES, 2006).

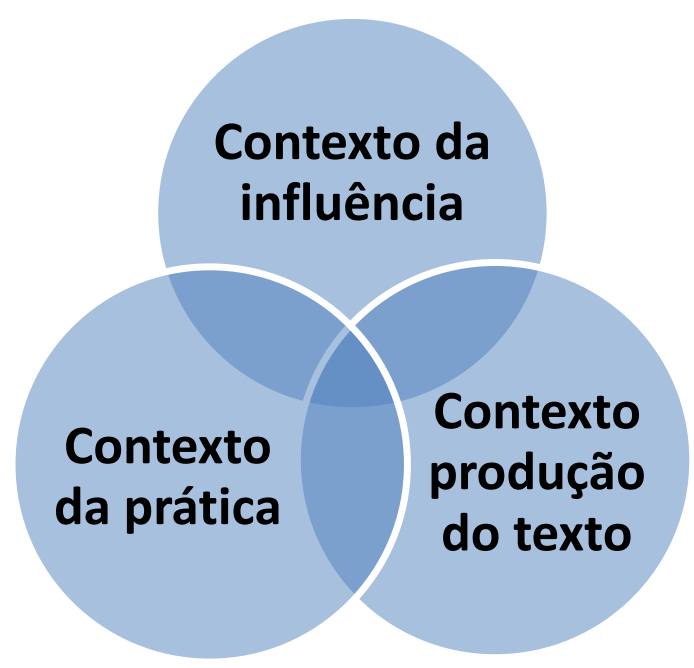

Figura 1. Contextos do modelo para análise de políticas públicas, segundo Ball e Bowe (1992).

Assim, vamos analisar neste artigo, o ensino de ciências com o Projeto UCA em Rondônia, considerando-se estes três contextos. 


\section{O projeto UCA e o contexto da influência}

Novas Tecnologias da Informação e Comunicação (NTICs), globalização e neoliberalismo são temas muito frequentes nos discursos sobre educação na atualidade. Uma reflexão acerca do atual papel e importância das tecnologias em nossa sociedade, também denominada de "sociedade da informação" ou "sociedade do conhecimento" se faz necessário no atual contexto de neoliberalismo globalizado e reestruturação produtiva do capital, o qual gera uma série de fenômenos, mudanças e reconfigurações nas relações entre governo, estado e mercado, segundo vários autores, tais como o surgimento da "tecnologização da cultura" ou "tecnocultura"; mutações na objetividade e subjetividade no mundo do trabalho, com perdas de direitos e sentidos e na vida das pessoas em geral - nas suas formas de ser e estar no mundo -, produzindo assim novas subjetividades e forjando personalidades, "[...] a qual se efetiva pela mediação da realidade histórico-social objetivando-se na e pela atividade histórica dos homens" (MARTINS, 2004, p. 85).

A educação, sendo socialmente determinada, não está alheia a esse processo, mas é impactada por várias políticas públicas, gerando assim vários fenômenos, tais como: intensificação do trabalho docente, dada as novas exigências postas para os professores decorrentes da introdução das tecnologias na escola; reestruturação do trabalho pedagógico, muitas vezes implicando em precarização do trabalho docente; mudanças na forma como a sociedade lida com o conhecimento e com os processos de ensino/aprendizagem; as formas de gestão e controle na busca por qualidade; cortes de gastos públicos com uma reestruturação da educação, tanto nos fins como nos processos que se desenvolvem nas escolas. Faz parte deste contexto de influência a revolução tecnológica propiciada pela informatização e comunicação, na qual, as máquinas, em seu atual estado de avanço tecnológico, têm permitido ao homem a ampliação não apenas de nossa capacidade cognitiva, com transferência de muitas de nossas funções cerebrais para elas, aumentando em muito "a capacidade de olhar, cheirar, sentir, registrar, memorizar etc." (GAMBOA, 1997, p. 35).

Fala-se muito na Sociedade da Informação ou Sociedade do Conhecimento como o paradigma para o Século XXI. O computador, a partir do advento da Internet tem possibilitado a produção e difusão de um número muito grande de informações que circulam numa rapidez jamais vista na história da humanidade. Mas, é bom lembrarmos a distinção entre informação e conhecimento que, reiteradas vezes e erroneamente, tem sido usadas como sinônimos, já que o acesso à primeira não implica a apropriação da segunda: "[...] elementos fragmentados constituem dados, os dados organizados constituem informação, e a informação elaborada pelo sujeito que a utiliza, na interação com a realidade, se transforma em conhecimento.". Já a sabedoria (uma virtude), resultaria de "[...] uma relação harmoniosa de conhecimento, ação e valores [...]". (DOWBOR, 2008, p. 33).

Desenvolvimento da autonomia, aprendizagem ao longo da vida, ensino por competência e as pedagogias do "aprender a aprender" são discursos que estão presentes nessa nova lógica em que a educação tem o papel de atender aos ditames do mercado, e que cumprem assim uma função ideológica, qual seja, a de atender a esse projeto societário (DUARTE, 2008). Este autor ainda fala acerca de uma das ilusões criadas por essa sociedade: a de que "[...] o conhecimento nunca esteve tão acessível como hoje, isto é, vivemos numa sociedade na qual o acesso ao conhecimento foi amplamente democratizado pelos meios de comunicação, pela informática, pela Internet etc.". (p. 14). 
Esta ilusão fica evidente quando analisamos o caso do poder da indústria farmacêutica, quando uma série de conhecimentos relevantes para a humanidade que trariam benefícios com impactos significativos nas populações mais pobres do planeta, por exemplo, são aprisionados sob a forma de patentes, estabelecendo hierarquia entre países desenvolvidos tecnológico-cientificamente e países que compram e são dependentes de tecnologias e conhecimentos produzidos, mas que não são socializados, apenas vendidos.

\section{Produção dos textos da política de informática na escola}

Em agosto de 2000, foi lançado no Brasil pela Presidência da República o Livro Verde (Green Book) da Sociedade da Informação no Brasil, contendo propostas para as áreas de educação, saúde, cultura, trabalho, transportes, governo eletrônico, política de desenvolvimento científico e tecnológico, entre outras, visando à construção de uma infraestrutura mundial a partir de investimentos em tecnologia e conectividade para se atender a um mercado calcado em um novo paradigma - o do "conhecimento".

O programa tem como objetivo estabelecer metas e fomentar iniciativas que visem o desenvolvimento econômico (criar condições para o país competir internacionalmente) e a inclusão social, baseados no uso das novas tecnologias de informação e comunicação. Para se atingir as metas estabelecidas, estava previsto o compartilhamento de responsabilidades entre poder público, sociedade civil e iniciativa privada, especialmente do setor de informática e das telecomunicações. Uma série de ações, medidas e programas foram implementados pelo governo brasileiro, visando construir as condições necessárias para incluir o Brasil na referida sociedade. No Portal do Governo Eletrônico podemos ver uma série de ações visando à inclusão digital, que foram criados ou reformulados para atender as estratégias traçadas, implementadas a partir dos seguintes programas ou projetos na educação: Banda Larga nas Escolas; Casa Brasil; Computadores para Inclusão; Oficina para Inclusão Digital; Observatório de Inclusão Digital; Projeto Cidadão Conectado; Computador para Todos; Programa GESAC; Programa de Implantação de Salas de Recursos Multifuncionais; Programa de Inclusão Social e Digital; ProInfo Integrado; Programa Telecentros Comunitários; Telecentros BR; Territórios Digitais; Programa Um Computador por Aluno.

Assim, a decisão de fornecer um computador por aluno se insere numa política que é implantada num contexto de neoliberalismo e de globalização da economia, onde o desenvolvimento do computador doméstico, especialmente sua miniaturização e a popularização de diversas tecnologias de comunicação e informação, contribuiu para que grande número de escolares em todo o mundo, cada vez mais, tenha acesso aos dispositivos informatizados que chegam à sala de aula. Cada vez mais poderosos em recursos, velocidade, programação e comunicação, os computadores podem permitir, dentre outras ações: fazer pesquisas diversas, simular inúmeras situações, descobrir novos conceitos, lugares e ideias.

Tudo isto levou ao desenvolvimento de um campo de pesquisa em que vários autores exploram o potencial destes recursos na educação, os quais buscam formas de utilização em sala de aula pelos professores e produzem textos, muitas vezes, repletos de prescrições. Segundo estes autores, as possibilidades vão desde seguir algo pronto, como nos infinitos tutoriais disponíveis, quanto apoiar-se em algo não pronto para, então, complementá-lo, criando algo diferente, inusitado, de maneira individual, personalizada ou coletiva, na sala de aula, com o auxílio do professor ou em qualquer outro ambiente da escola, por exemplo. 
Autores como Moran e cols. (2009); Almeida e Prado (2011), entre outros, consideram a sala de aula como um espaço privilegiado de aprendizagem, mas não o único, sendo esse mais um ambiente de aprendizagem e de práticas sociais, já que a aprendizagem pode ter lugar em diferentes contextos e situações, como no pátio, na quadra poliesportiva, na biblioteca ou em qualquer outro ambiente disponível da escola ou fora do seu espaço físico.

Para Giordan (2008), a comunicação mediada por computadores estimula o diálogo dos alunos entre si e com seus professores e depois da disseminação da Internet, uma das formas mais instigadas nas escolas, tanto dentro quanto fora da sala de aula, é a utilização da rede pelos alunos para fazerem perguntas e esperar respostas dos inúmeros tutoriais disponíveis para resolver questões e problemas suscitados em sala de aula pelo professor, por colegas ou por si mesmo.

Isto exige que o professor planeje atividades que possam ser mediadas pelo correio eletrônico, chats, fóruns ou por outra ferramenta que propicie o diálogo e a interação entre aluno-aluno e entre aluno-professor. Por meio de atividades estruturadas, a dinâmica das interações que ocorrem em sala de aula, mediadas pelo computador, podem estimular os alunos a perguntarem e a responderem mais sobre questões abordadas nas aulas sobre certos conteúdos do currículo ou por questões referentes a curiosidades levantadas por estes. Podendo inclusive, ter em muitos momentos, o aluno como ocupante de uma posição de controle sobre o fluxo do diálogo estabelecido, enfatizando o desenvolvimento de suas habilidades e de suas capacidades, promovendo seu desenvolvimento como um sujeito ativo. (LEME, 2011).

O computador interligado à rede pode ajudar o professor a não centralizar a obtenção do conhecimento em si mesmo, observando as peculiaridades do saber a ser construído, incentivando a troca de informações dos resultados que vão sendo obtidos por seus alunos, mesmo quando parciais, para que todos possam obter benefícios dos resultados dos outros alunos. Aprendendo através da colaboração, mais do que pela competição e estar sempre atento aos vários ritmos individuais de descoberta de seus alunos, o que servirá de elo entre a turma. (GIORDAN, 2008; LEME, 2011).

Segundo Almeida e Valente (2011), a ideia de cada aluno ter o seu próprio computador já é bem antiga e foi idealizada bem antes da existência dos microcomputadores. Ela foi proposta por Alan Kay, em 1968, após ter visitado Seymour Papert no Massachusetts Institute of Tecnology (MIT). A proposta era que cada aluno utilizasse um computador para concretizar suas ideias através da construção de simulações. Kay idealizava seu computador portátil como um meio para expressar e comunicar o que o aluno estava pensando. A proposta de Kay foi materializada em 1972 com o Dynabook, que pode ser considerado o precursor dos laptops atuais. Estes, além de serem acessíveis como os livros, deveriam ser utilizados para concretizar suas ideias por meio da construção de simulações, como, por exemplo, simular fenômenos de Ciências, Biologia, Física, Química e Matemática.

Essa ideia foi apresentada aos chefes de estado presentes no Fórum Econômico Mundial que ocorreu em Davos / Suíça, que foram desafiados pelo pesquisador do MIT, Nicholas Negroponte, a se engajarem num esforço global visando universalizar o acesso e uso das TICs. Uma ideia inovadora, segundo seus proponentes, que consistia em um laptop de $\cup \$ 100$ dólares distribuídos às escolas, garantindo a todas as crianças o direito ao uso de seu próprio computador, lema esse que é adotado pela instituição One Laptop per Child (OLPC). O então presidente do Brasil, Luiz Inácio Lula da Silva, naquele mesmo ano, visando à implementação do programa, a inserção da indústria brasileira na cadeia produtiva, bem 
como possibilitar a inclusão digital, inserção e uso intensivo das TICs nas escolas e consequente melhoria na qualidade da educação pública, determinou a criação de um grupo interministerial para proceder à avaliação e elaboração de um relatório que subsidiasse o poder público à tomada de decisão da adoção da ideia.

Após criação de um grupo de trabalho formado por professores-pesquisadores para definir as estratégias pedagógicas do programa (GT-UCA) e doação dos equipamentos por parte das empresas que desenvolveram protótipos do laptop (Intel, Telavo e da organização não-governamental One Laptop per (Child) iniciou-se em 2007 a Fase I ou Fase Pré-piloto, visando avaliar o uso pedagógico dos laptops educacionais em cinco escolas de municípios de diferentes regiões brasileiras: Porto Alegre-RS; periferia da cidade de São Paulo; Piraí / RJ; Palmas /TO e zona central de Brasília.

Em 2010, o Projeto UCA entrou em sua Fase II, denominada Fase Piloto em cerca de 300 escolas públicas das redes de ensino estaduais e municipais, distribuídas em todas as unidades da federação, escolhidas por critérios definidos por: Conselho Nacional de Secretários Estaduais de Educação (CONSED), União Nacional dos Dirigentes Municipais de Educação (UNDIME), a Secretaria de Educação a Distância do Ministério da Educação (SEED/MEC) e assessores da Presidência da República. Os critérios básicos utilizados foram: ter em torno de 500 (quinhentos) alunos e professores em seu quadro; possuir "obrigatoriamente" energia elétrica para carregamento dos laptops e armários para armazenamento dos equipamentos; preferencialmente, deveriam ser pré-selecionadas escolas com proximidade a Núcleos de Tecnologias Educacionais (NTE) ou similares, Instituições de Educação Superior pública ou Escolas Técnicas Federais. Pelo menos uma das escolas deveria estar localizada na capital do estado e uma na zona rural; as Secretarias de Educação Estaduais ou Municipais de cada uma das escolas selecionadas deveriam aderir ao projeto através do envio de ofício ao MEC e assinatura de Termo de Adesão, no qual se manifesta solidariamente responsável e comprometida com o projeto; para cada escola indicada, a Secretaria de Educação Estadual ou Municipal deveria enviar ao MEC um ofício do(a) diretor(a) da escola, com a anuência do corpo docente, aprovando a participação da escola no projeto.

A escolha destas 300 escolas ocorreu com a participação das Secretarias Estaduais de Educação, União Nacional dos Dirigentes Municipais de Educação (UNDIME) e o MEC. Por iniciativa dos governos Federal, Estaduais e Municipais, o projeto foi implantado também em seis municípios brasileiros onde todas as suas escolas foram atendidas e nestes, o projeto foi chamado de UCA Total. São eles: Barra dos Coqueiros /SE, Caetés /PE, Santa Cecília do Pavão /PR, São João da Ponta /PA, Terenos /MS e Tiradentes /MG.

Todos os alunos e professores das escolas selecionadas em 2007 receberam, em 2010, um computador portátil, o laptop educacional, produzido pelo consórcio CCE / DIGIBRAS / METASYS, o qual foi dado como vencedor do pregão no 107/2008 para o fornecimento de 150.000 equipamentos. Como pode ser observado (Figuras 2A e 2B), o laptop educacional CM-52C distribuído para as escolas participantes do Projeto UCA - Fase II é um equipamento revestido externamente por um material emborrachado para conferir maior resistência a quedas e dar conforto durante o seu manuseio.

Também possui alças que conferem ao usuário maior facilidade durante seu transporte. Cada uma dessas escolas deveria receber do governo federal, além dos laptops para alunos e professores, infraestrutura para acesso à Internet e capacitação para gestores e professores na utilização dessa tecnologia. Quanto à adaptação da rede elétrica e compra 
de armários para armazenamento e carregamento dos laptops ficaram sob a responsabilidade das Secretarias de Educação estaduais e municipais.

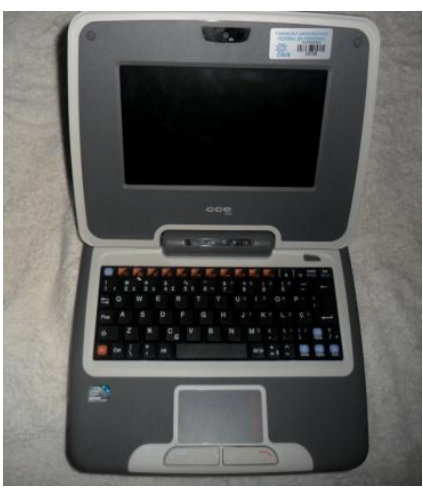

Figura 1A: Laptop Educacional aberto

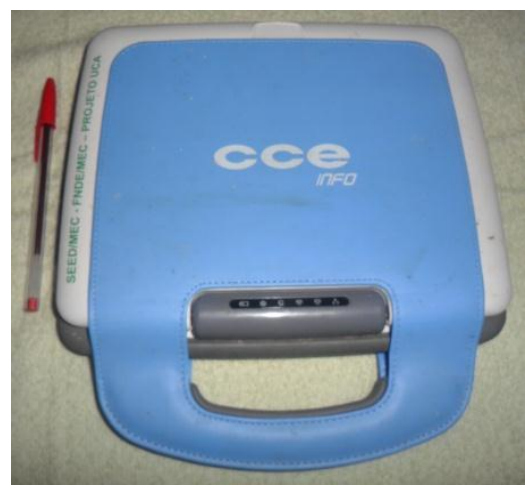

Figura 1B: Laptop Educacional fechado.

É necessário reconhecer que a utilização das Tecnologias Digitais de Informação e Comunicação (TDIC) na educação avança a cada dia fazendo com que seja necessária a criação de mecanismos para a utilização dessas tecnologias como um recurso pedagógico capaz de colaborar com o processo de ensino, e por consequência, proporcionar a oportunidade de que os atores escolares criem e socializem novas formas de aplicação dessas tecnologias em diversas áreas ou disciplinas escolares. Mendes e Almeida falam da importância do professor nesse processo, já que estes autores afirmam que a função do professor na sala de aula "[...] é o de um mediador, facilitador, incentivador e motivador da aprendizagem, criador de estratégias didáticas que propiciam o diálogo, a participação, a exploração, a reflexão e a construção do conhecimento [...]". (ALMEIDA \& PRADO, 2011, p. 52). Na perspectiva de viabilizar a integração do laptop educacional ao cotidiano escolar, estas autoras destacam a importância de que os professores tenham a oportunidade de participarem de programas de formação continuada com foco nas práticas baseadas na utilização dessa tecnologia em sala de aula, no qual estes possam ter a oportunidade de refletir sobre a mesma, podendo identificar e analisar as mudanças ocorridas, as possíveis dificuldades enfrentadas e as decisões necessárias para que essas práticas possam se concretizar.

\section{O projeto UCA em Rondônia: o contexto da prática}

No estado de Rondônia, o Projeto UCA- Fase II ou Fase Piloto contemplou oito escolas públicas em sete municípios: Ariquemes, Cacaulândia, Ji-Paraná, Ouro Preto D'Oeste, Porto Velho (duas escolas), Rolim de Moura e Vilhena. A chegada dos laptops educacionais do Projeto UCA às escolas, em meados de 2010, para serem utilizados por alunos e professores nas salas de aula provocou inquietações, expectativas e mudanças na dinâmica escolar, as quais vêm sendo registradas no desenvolvimento do Projeto através de várias ações de pesquisa e extensão que estão acontecendo simultaneamente pela integração do processo de formação de recursos humanos envolvidos com a operacionalização do projeto-piloto com um projeto de investigação, ambos coordenados por professores-pesquisadores da Universidade Federal de Rondônia (UNIR). (MARTINES, 2011).

A formação de professores e gestores foi planejada para ocorrer durante a implantação do Projeto UCA - Fase Piloto, sob a coordenação do MEC / SEED através do Curso 
Formação Brasil executado por uma ampla rede de pessoas e instituições. O Projeto UCA/RO foi implantado em parceria com a Instituição de Ensino Superior (IES) Global representada pela UNICAMP através de uma equipe de pesquisadores-formadores do Núcleo de Informática Aplicada à Educação (NIED), coordenado pelo Dr. José Armando Valente, ao qual estão interligadas as IES Locais dos Estados do Pará (UFPA), Acre (UFAC) e Rondônia (UNIR) e algumas escolas do Estado de São Paulo, o que facilita a interação com o sistema nacional e regional do Projeto UCA - Fase II.

Esta rede começou a se formar em setembro de 2010 durante o I Encontro UCA-Norte (UCA-NO) que ocorreu em Belém/PA, sob a coordenação da equipe de pesquisadores do NIED/ UNICAMP responsável pelo programa de formação. O processo de formação dos professores na ação se desenvolve com foco na realidade de cada escola e no contexto da sala de aula, à medida que o uso dos laptops educacionais por professores, alunos e gestores for ocorrendo. Essa formação em serviço tem como pressupostos: a interação e a reflexão sobre a integração entre a prática pedagógica, o currículo, as tecnologias e as teorias educacionais que permitem compreender e transformar as práticas, com vistas à melhoria da aprendizagem do aluno. (MARTINES, 2011).

Em nível estadual, o UCA/RO - Fase II foi coordenado de forma colaborativa pela UNIR, através do Laboratório de Ensino de Ciências (EDUCIENCIA) e pela Secretaria de Educação do Estado de Rondônia (SEDUC/RO), através do Programa de Tecnologia Educacional (PTE). Integram ainda esta rede, os formadores e tutores dos NTEs e os professores e gestores das escolas distribuídas nos sete municípios (cinco escolas estaduais e três municipais). Conta ainda com o apoio das Secretarias Municipais de Educação (SEMEDs) e dos Núcleos de Tecnologia Municipais (NTM) de Porto Velho e de Ji-Paraná.

A primeira oferta do curso Formação Brasil se desenvolveu simultaneamente ao Projeto de Pesquisa Integrado com Extensão "Estudo de Caso da Implantação do Projeto UCA em Rondônia", aprovado pelo Conselho Nacional de Desenvolvimento Científico e Tecnológico (CNPq) e que os pesquisadores do EDUCIENCIA vêm executando desde novembro de 2011. A metodologia da formação para professores do Projeto UCA, em Rondônia, engloba três dimensões, que se encontram imbricadas: Tecnológico: apropriação e domínio dos recursos tecnológicos voltados para o uso do sistema Linux Educacional e de aplicativos existentes nos laptops educacionais; Pedagógico: uso dos laptops nos processos de ensinar e aprender, bem como na gestão de tempos, espaços e relações entre os protagonistas da escola, do sistema de ensino e da comunidade externa; Teórico: busca da articulação de teorias educacionais que permitam compreender criticamente os usos em diferentes contextos e reconstruir as práticas pedagógicas e de gestão da sala de aula e da escola.

Em cada escola participante do Projeto UCA foi designado pela própria escola um professor ou coordenador ou orientador educacional para atuar como Coordenador UCA, conforme sugere um acordo de cooperação técnica entre MEC e estado. Estes assumiram um importante papel no processo de formação para a utilização dos laptops por alunos e professores, pois é ele quem dá o suporte pedagógico diário para os professores, auxiliando, inclusive, no desenvolvimento e planejamento de atividades com esse recurso tecnológico.

O curso Formação Brasil do Projeto UCA se iniciou em outubro de 2010 e já aconteceram seis encontros da equipe UCA (formada pelos professores-pesquisadores da UNIR e técnicos da SEDUC/RO) com os Coordenadores UCA das oito escolas-piloto, com os objetivos de: planejar as ações de formação, avaliar as atividades desenvolvidas durante 2011 a 2013 em suas escolas, visando uma melhor integração e socialização de experiências 
entre as escolas participantes do Projeto UCA, além de planejar as ações futuras diante das mudanças contextuais que vão ocorrendo. Esses encontros ocorreram em locais diversos, de acordo com as possibilidades logísticas da equipe de organização, nos quais os Coordenadores UCA (que aqui recebe nome fictício de flores) de cada escola (nome fictício de aves da Amazônia) foram fornecendo informações sobre atividades de ciências realizadas pelos professores nas escolas, as quais estão sintetizadas na Tabela 1.

Tabela 1. Relação de atividades realizadas em Ciências utilizando o Laptop educacional nas escolaspiloto do Projeto UCA/RO, segundo relatos nos Encontros da Equipe UCA/RO.

\begin{tabular}{|c|c|}
\hline Escola & 2011 \\
\hline Jacumirim & $\begin{array}{l}\text { Pesquisas na Internet sobre: recursos naturais, sistema digestivo, as usinas hidrelétricas do Madeira; } \\
\text { Elaboração de texto sobre desmatamento e queimadas e postagem no blog; } \\
\text { Projeto: "Astronomia e Astronáutica"; Prática: Medir o nível de Ph das substâncias com água do repolho roxo } \\
\text { com auxilio de vídeos no youtube; Consultas ao site: www.soq.com.br (Portal de Química); criação de e-mails } \\
\text { para cada aluno e a criação e manutenção do Blog de Ciências: http://escolaliraciencias.blogspot.com.br; } \\
\text { Ciclo da água - Animação Link: http://www.youtube.com/watch?v=et05vorLkxY; Processo digestivo Link: } \\
\text { http://www.youtube.com/watch?v=; Movimento MRU; MRUV; Velocidade; Aceleração; queda dos corpos. } \\
\text { Visita ao site: http://www.sofica.com.br e postagem no blog de Ciências }\end{array}$ \\
\hline Rouxinol & Pesquisa na Internet sobre o Sistema solar. \\
\hline Curió & Projeto: "Feira Cultural e Científica": pesquisa na Internet e digitação de textos e apresentações. \\
\hline Arara & $\begin{array}{l}\text { Pesquisa na Internet sobre: órgãos dos sentidos; Projeto "Feira de Ciências": pesquisa na Internet e digitação } \\
\text { de textos e preparação de apresentações. }\end{array}$ \\
\hline Canário & Projeto "Escola limpa". Com postagem no blog \\
\hline Escolas & 2012 \\
\hline Jacumirim & $\begin{array}{l}\text { Pesquisa na Internet e desenho no tux paint sobre degradação ambiental; Projeto Interdisciplinar de } \\
\text { aprendizagem: "O lugar onde vivo"; Digitação de Relatório de aula prática sobre a ação do ácido acético } \\
\text { sobre o cálcio da casca do ovo de aves; Projeto "Astronomia e Astronáutica"; Vídeos e desenho no Tux paint } \\
\text { referente ao tema: Lixo e cuidados com o solo; Aula de Química Inorgânica: ácidos, bases, sais e óxidos - } \\
\text { Utilizando o site da escola para realização da atividade; Vídeos sobre o sistema digestivo. }\end{array}$ \\
\hline Bem-ti-vi & $\begin{array}{l}\text { 1ª Mostra de Iniciação Cientifica na Educação Básica: pesquisa para visualização de fotos, vídeos no youtube } \\
\text { do sistema digestivo e respiratório. }\end{array}$ \\
\hline Rouxinol & $\begin{array}{l}\text { Pesquisa na Internet e jogos sobre Cadeia alimentar; Pesquisa na Internet sobre hanseníase; } \\
\text { Projeto "Solo" em parceira com EMBRAPA; Filmagem de plantas. }\end{array}$ \\
\hline Beija- flor & Projeto Interdisciplinar "Folclore": comidas típicas, plantas medicinais. \\
\hline Tucano & $\begin{array}{l}\text { Pesquisa na Internet sobre tipos de poluição, prejuízos da poluição para o meio ambiente, reconhecimento } \\
\text { do meio ambiente e lixo hospitalar; Jogos educativos sobre preservação do meio ambiente e reciclagem; } \\
\text { Construção de tabelas e gráficos sobre quantidade de resíduos sólidos recolhidos pelos alunos. }\end{array}$ \\
\hline Curió & $\begin{array}{l}\text { Pesquisas na Internet sobre: vírus, biodiversidade, tipos de solos; Projeto: "Feira Cultural e Científica"; e Projeto } \\
\text { "Ecossistema". }\end{array}$ \\
\hline Arara & $\begin{array}{l}\text { Pesquisas na Internet sobre: drogas lícitas e ilícitas, os ciclos da água e da natureza, sobre cadeia alimentar, } \\
\text { sistema circulatório, sistema solar, o corpo humano, ciclo da água, plantas e alimentos, o solo na agricultura, } \\
\text { meio ambiente e poluição e seres vivos. }\end{array}$ \\
\hline Canário & $\begin{array}{l}\text { Projeto de aprendizagem: "Quantos meninos cabem em um elefante?" } \\
\text { Projeto Xadrez para desenvolvimento de raciocínio lógico. }\end{array}$ \\
\hline Escolas & Fevereiro-junho/2013 \\
\hline Jacumirim & $\begin{array}{l}\text { Projetos de Geociências envolvendo as disciplinas de Ciências e Geografia: "Amazônia vai ao Ártico" } \\
\text { (Programa Semana Polar); "Conhecendo o Universo" (Olímpiada de Astronomia e Astronáutica e lançamento } \\
\text { de foguetes); "Um lixo a menos" } \\
\text { Blogs para divulgação científica e socialização com os alunos; } \\
\text { Página no Facebook para socialização e divulgação de atividades } \\
\text { Histórias em Quadrinhos virtuais - HQ's, }\end{array}$ \\
\hline Tucano & $\begin{array}{l}\text { Projeto: "Preservação Ambiental"; Desenhos de animais selvagens e domésticos no Tux paint; } \\
\text { Pesquisa na Internet sobre papel reciclado. }\end{array}$ \\
\hline Arara & Pesquisa na Internet e desenho no tux paint sobre animais vertebrados e invertebrados \\
\hline Canário & $\begin{array}{l}\text { Projeto em parceria com o Instituto Federal de Rondônia (IFRO): "Monitoramento da água"; Projeto de } \\
\text { preservação das matas ciliares; Projeto Xadrez para desenvolvimento de raciocínio lógico. }\end{array}$ \\
\hline
\end{tabular}

Destacamos que esta Tabela pode não trazer todas as atividades que foram realizadas pelos professores, uma vez que a maioria delas foi fornecida pelos Coordenadores UCA na 
Escola e alguns podem ter omitido a informação, por esquecimento ou desconhecimento do trabalho feito por algum/a professor/a.

Como observamos na Tabela 1 , poucas atividades de Ciências utilizando o laptop educacional foram realizadas em 2011. Neste período, correspondente ao início da formação dos professores, gestores e Coordenadores do Projeto UCA, houve uma interrupção no primeiro semestre deste ano, devido à descontinuidade da política com a mudança do governo Lula para o da presidente eleita Dilma Roussef, com reorganização dos ministérios e secretarias no âmbito federal e também do governo estadual com a tomada de posse de novo governador.

Vários outros fatores podem ter influenciado as escassas atividades com os laptops, segundo os Coordenadores UCA, tais como: na maioria das escolas, por questões de estrutura física os laptops permaneceram armazenados nas caixas, uma vez que a maioria das Secretarias de Educação não providenciou a compra dos armários para armazenamento e carregamento dos laptops, chegando ao ponto, como aconteceu na Escola Beija-flor, de não serem disponibilizados aos alunos em nenhuma disciplina escolar neste ano. As Secretarias também não haviam feito a adaptação da rede elétrica com instalação de tomadas nas salas para o carregamento dos laptops e mudanças mais amplas da rede para suportar o aumento de demanda criado pelos novos equipamentos, na maioria dos casos. Estas condições obrigam os alunos e professores das escolas que não tiveram a infraestrutura adaptada para o projeto UCA a transportar as máquinas de um local de armazenamento e carregamento das baterias (geralmente, o Laboratório de Informática que dispõe de ar condicionado) para a sala de aula a cada utilização, o que toma muito tempo e desestimula o seu uso.

Há também resistência à sua utilização por parte de alguns professores, como é o caso do professor de Ciências citado pelo Coordenador UCA da escola Escola Beija-flor, que nem sequer participou do curso de formação. As escolas que utilizaram os laptops em 2011 o fizeram em grande parte para acessar informações na Internet, digitar textos e para concretizar projetos escolares propostos por seus professores. O destaque positivo para a utilização de atividades em Ciências em 2011 foi na Escola Jacumirim pela professora Amarilis, pois esta tem domínio das tecnologias disponibilizadas pelo Projeto UCA e é habilitada em Pedagogia para ensino nos anos iniciais do ensino fundamental ( $1^{\circ}$. a $5^{\circ}$. Ano) e para o Ensino de Ciências e Biologia nos anos finais do ensino fundamental ( $6^{\circ}$. a $9^{\circ}$. Ano), enquanto a maioria dos professores das oito escolas só possui formação em Pedagogia.

No ano 2012, como pode ser observado na Tabela 1, notou-se uma crescente utilização dos laptops educacionais na disciplina de Ciências, como: desenvolvimento de diversos projetos de aprendizagem, construção de textos, filmagens, postagens em blogs e inúmeras pesquisas na Internet. Esse fato pode ser atribuído a uma maior segurança na utilização e familiarização dessa tecnologia por professores, que passaram a disponibilizá-la mais vezes aos seus alunos em suas aulas, inclusive na escola Beija-flor, que não havia utilizado o laptop no ano 2011.

Até o mês de junho de 2013, diversas atividades em Ciências utilizando o Laptop foram realizadas, como: projetos de aprendizagem, desenhos no Tux paint, postagens em Blogs e no Facebook e pesquisas na Internet. Como mencionado por Coordenadores UCA no VI Encontro UCA, boa parte dos professores já adquiriram maior confiança na utilização dos laptops, inclusive inseriram este recurso em seus planejamentos no início desse ano letivo. A infraestrutura também melhorou na maioria das escolas, especialmente pela mobilização das comunidades para suprir as carências que não foram resolvidas pelo poder público, 
mas não obtivemos informações através dos Coordenadores UCA das escolas Bem-ti-vi, Beija-flor, Curió e Rouxinol sobre a realização de atividades em Ciências com a utilização do laptop educacional neste ano.

A Escola Beija-flor permanece com problemas em relação à utilização dos laptops tanto na disciplina de Ciências quanto nas demais disciplinas escolares, especialmente no segmento final do ensino fundamental, pelos mesmos motivos apontados pelos Coordenadores UCA em 2011 e 2012, além de se tratar de uma escola rural pequena, com poucas turmas de $6^{\circ}$. a $9^{\circ}$. Ano. Isto obriga a maioria dos professores a dar aula em mais de uma escola e não permanecer na escola para planejamento, o que é fundamental neste caso. Existem também problemas graves com a Internet (GESAC), falta de armários e tomadas nas salas, aulas de uma hora por disciplina, entre outros.

Podemos observar que, mesmo com inúmeras dificuldades de infraestrutura, uma variedade de atividades em Ciências foram realizadas de 2011 até meados de 2013, porém, as atividades que mais foram realizadas com os laptops educacionais, até o momento, foram o acesso a informações de textos e imagens na Internet, reproduzindo em grande parte o que já é feito no modo tradicional com o auxílio de livros, lápis e papel.

O fato de o laptop estar conectado a Internet facilitou a pesquisa por professores e por alunos em vários momentos. Com riqueza de imagens e múltiplas opções de pesquisas, a Internet é um atrativo inegável para alunos e professores, tornando-se condição básica, na maioria dos casos, para a utilização dos laptops. Entretanto, a maioria das escolas enfrenta problemas com a Internet: dificuldade de conexão, baixa capacidade disponível, queda com a ligação de muitos computadores ao mesmo tempo, quebra de equipamentos e dificuldades para conserto ou reposição de peças, segundo relatos dos Coordenadores UCA.

Em algumas escolas foram realizados projetos, interdisciplinares ou específicos de Ciências, com o auxílio do laptop, a partir da intenção pedagógica dos professores. Alguns projetos são definidos como parte de um contexto significativo para os alunos, a partir do seu interesse, ajustando-se ao nível das dificuldades, de acordo com a Zona de Desenvolvimento Proximal individual ou de uma forma coletiva, assumindo uma atitude construcionista, que têm a meta de produzir a maior aprendizagem a partir do mínimo ensino, no qual os alunos possam construir seus métodos de resolução de problemas, de acordo com seus próprios pensamentos, que devem ser respeitados e incentivados por seus professores. (ALMEIDA \& VALENTE, 2011),

Um exemplo que seguiu esta concepção é o projeto de aprendizagem "Quantos meninos cabem em um elefante?" desenvolvido por uma professora de $4^{\circ}$. Ano da Escola Canário. A partir da pergunta feita por um garotinho que estava tendo dificuldades de aprendizagem e do esforço de sua professora para Ihe ensinar, sem muito sucesso, por sugestão da Coordenadora UCA na Escola e com sua colaboração na elaboração do projeto, a professora utilizou sistematicamente o laptop em sala de aula, apesar da dificuldade de acesso da Internet na zona rural. A professora e a Coordenadora UCA pesquisavam na rede e salvavam no computador UCA, usado como servidor na escola, os arquivos selecionados e as crianças os acessavam com os laptops para responder questões que iam surgindo no desenvolvimento do projeto, como: quanto mede a pata do elefante? Será que é maior que um prato? Onde vivem os elefantes? Como se alimentam e se reproduzem?

Outro exemplo da utilização dos laptops conectados na Internet nestas escolas foram postagens de atividades realizadas nas escolas nos chamados Blogs, para divulgação, como 
ocorreu nas escolas Jacumirim e Canário. De acordo com Giordan (2008), os Blogs são espaços onde as pessoas podem escrever sobre diversos assuntos. São similares a uma página WEB com a facilidade de não ser preciso desenvolvê-lo em HTML. São compostos em grande parte por textos, imagens, sons e links de páginas da WEB ou mesmo de outros Blogs. O Blog tornou-se uma ferramenta que pode oferecer espaços para se inserir comentários, garantindo a interação entre autores e leitores, entre professores-alunos e alunos-alunos. Não podemos negar que são um fenômeno atual da Internet e segundo Giordan (2008), assumem um extremo valor para interpretarmos o cenário atual de mudanças em que vivemos, com ampliação do universo dos interlocutores envolvidos. $E$ ainda segundo Giordan (2008), as narrativas postadas nos Blogs se tornam um instrumento inusitado para construir memórias coletivas de som, imagens e vídeos.

Giordan fala que a transformação das formas de comunicação na escola ainda é uma questão em aberto, pois a organização escolar segue firmemente a tradição fordista de produção do conhecimento, na qual as aulas têm hora marcada para começar e para terminar. Essas coerções temporais não são de todo compatíveis com a comunicação mediada, mas não há dúvida de que, se um professor desejar incorporá-la à sua prática, não apenas a negociação dos significados, mas, fundamentalmente, a negociação da agenda da aula poderá ser afetada, devendo estender a sala de aula para ambientes de comunicação mediada pelo uso do computador. É neste transbordamento da sala de aula para o ciberespaço que se encontra o maior desafio para o professor, "[...] pois, ali, a temática, a interlocução, os meios de comunicação não são de seu domínio exclusivo, mas estão distendidos na direção dos alunos". (2008, p.106).

As escolas Rouxinol e Tucano utilizaram diversos jogos educativos em suas aulas de Ciências. Giordan (2008) aponta para a necessidade de se estudar esse fenômeno, que há muito tempo vem sendo considerado como uma das principais formas de ação para fomentar o desenvolvimento sociocognitivo dos alunos e pode acabar por alterar a rotina de crianças e adolescentes nos trazendo questões importantes para um futuro debate, com a perspectiva de compreender como a ampliação da interlocução e a aproximação entre visões de mundo distintas podem contribuir para o ensino e a aprendizagem.

O YouTube foi uma ferramenta utilizada na escola Bem-ti-vi para assistir vídeos relacionados a disciplina de Ciências. O Youtube é considerado hoje, como a melhor biblioteca de vídeo do mundo, tendo como objetivo o compartilhamento de vídeos diversos. (CRUZ, 2008). O Facebook, site de rede social é considerado hoje uma ferramenta líder, apresentando inúmeras aplicações e podendo ser utilizado também na educação. Os usuários podem criar seus perfis com ou sem fotos e listas de interesses pessoais, sendo possível trocar mensagens privadas e/ou públicas entre os grupos de amigos. A professora Amarilis da Escola Jacumirim já se utiliza de uma página no Facebook para divulgação de conteúdos de Ciências e para fomentar discussões e comentários dos alunos. As estratégias de ensino e atividades apresentadas para as ferramentas You Tube e do Facebook nos fazem pressupor que, se os professores conhecem os interesses dos alunos, as aulas serão mais prazerosas tanto para os alunos como para os professores, o que pode até mesmo facilitar o aprendizado.

Mendes e Almeida (2011) destacam que as características de conectividade e de mobilidade dos laptops educacionais são capazes de possibilitar diferentes maneiras de comunicação e interação, o que torna possível buscar informações, comunicação à distância e a facilidade de se trabalhar conteúdos, como os de Ciências, em qualquer lugar, tempo e espaço. Os laptops educacionais foram utilizados por alunos e professores para realizarem 
atividades de Ciências em vários ambientes físicos das escolas como: na sala de aula, no laboratório de informática, no pátio da escola e em seu entorno; para realizarem diversas atividades, como: pesquisas na Internet, construção de textos, postagens em blogs, registro fotográfico, filmagens do ambiente natural e artificial e para apresentação de trabalhos. 0 horário de utilização dos laptops educacionais seguiu um roteiro estabelecido e determinado pela escola, que, em geral, relacionou-se com a disponibilidade da Internet e com a condição de carga elétrica dos laptops, já que em algumas escolas, a rede elétrica não suporta vários laptops ligados ao mesmo tempo.

\section{Considerações finais}

Para garantir as condições necessárias de desenvolvimento do capitalismo nos novos moldes impostos pelo neoliberalismo e globalização da economia, ancorados na informação e no conhecimento, inúmeros atores compõem a nova cena, criando as condições ideológicas e materiais para o surgimento e desenvolvimento dessas novas configurações, colocando a educação a serviço do mercado. Organismos internacionais como o Banco Mundial, BIRD, FMI, OMC e regionais como a UNESCO, UNICEF, CEPAL, bem como órgãos públicos e privados comparecem como estes atores na elaboração das políticas públicas educacionais nas últimas décadas. Este cenário se faz presente na política pública de informatização na educação brasileira.

Em Rondônia, o Projeto UCA vem sendo implantado com um projeto de formaçãoinvestigação, no qual a formação ocorre dentro de uma ampla rede que vai se consolidando entre diversas Instituições de Ensino Superior (IES), técnicos dos sistemas de ensino federal, estadual e municipal, as escolas e as comunidades locais. Essa rede liga os grupos de gestores, formadores, pesquisadores e professores produzindo movimentos contínuos de troca, que poderão possibilitar o desenvolvimento e os ajustes necessários ao processo de formação, respeitando as diversidades regionais e locais das escolas e seus professores.

Destacamos que se está no início de um programa federal que visa inserir as Novas Tecnologias de Informação e Comunicação (NTICs) nas escolas, com uma inovação, a de disponibilizar um computador a cada aluno, bem como uma rede Wi-fi na escola, para acesso à rede mundial de computadores (Internet) sem a necessidade de conexão física. A chegada dos laptops educacionais nas escolas traz novos desafios para a comunidade escolar. Em tempos de acirrado desenvolvimento tecnológico, em que a Internet ocupa espaço privilegiado nas ações e nas relações humanas, a escola não pode e não deve se posicionar à margem do processo. No entanto, o uso educacional das TDIC exige tanto o domínio das suas principais funcionalidades e modos de operação dos recursos tecnológicos disponíveis quanto a identificação de suas potencialidades pedagógicas para que o professor possa inserir seu uso em atividades em consonância com as intenções que se encontram implícitas ou explícitas na proposta curricular.

Apesar de o design dos laptops propiciarem aos alunos a facilidade de transporte, como um caderno, em relação a atividades de Ciências, que é o foco desta pesquisa, em algumas escolas, os laptops não foram entregues aos alunos para que os mesmos levassem para casa ou para que utilizassem livremente nas aulas, na escola ou onde quisessem. Diversos fatores foram citados pela equipe gestora das escolas para tal comportamento que, relacionam-se ao receio que os mesmos possuem de que os laptops possam ser 
danificados pelos alunos ou por outrem e até mesmo que possam ser furtados ou roubados por pessoas mal intencionadas.

Consideramos, então, relevante a realização de pesquisas na intersecção do campo das Tecnologias na Educação com a Psicologia Escolar Crítica, que analisa os discursos presentes em três contextos diferentes que se influenciam mutuamente, de projetos como o aqui analisado, por tratar-se de projeto considerado inovador nos processos de ensinoaprendizagem mediados pelo uso de dispositivos portáteis por professores e alunos da rede pública de ensino, mas que se revestem de grande complexidade pela imbricação dos diferentes contextos implicados nas políticas públicas educacionais na atualidade.

\section{Referências}

ALMEIDA, M.E.B. de; PRADO, M.E.B.B. (Orgs.). O Computador portátil na escola: mudanças e desafios nos processos de ensino e aprendizagem. São Paulo: Avercamp, 2011. p. 34-48

ALMEIDA, M. E. B. de; VALENTE, J. A. Tecnologias e currículo: trajetórias convergentes ou divergentes? Coleção: Questões Fundamentais em Educação. Vol.10. São Paulo: Paulus, 2011.

BALL, S. J. Sociologia das políticas educacionais e pesquisa crítico social: uma revisão pessoal das políticas educacionais e da pesquisa em política educacional. IN: BALL, S. J.; MAINARDES, J. (Org). Politicas Educacionais: questões e dilemas. São Paulo: Cortez, 2011. p. 21-53.

BRETON, P. História da Informática. São Paulo: Editora Unesp, 1991.

CRUZ, S. Blogue, YouTube, Flickr e Delicious: Software Social. In CARVALHO, A. A. A (org.). Manual de ferramentas da WEB 2.0 para professores. Portugal: Ministério da Educação/DGIDC, 15-40. 2008.

DOWBOR, L. Tecnologias do Conhecimento. Vozes: Petrópolis, 2008.

DUARTE, N. Sociedade do conhecimento ou sociedade das ilusões? Quatro ensaios críticos dialéticos em filosofia da educação. Campinas, SP: Autores associados, 2008.

GAMBOA, S. S. Revolução Informacional: Pontos de vista para o debate sobre a sociedade da informação. Transinformação, v. 9, n. 1, p. 32-42, janeiro/abril, 1997.

GIORDAN, M. Computadores e linguagens nas aulas de ciências: uma perspectiva sociocultural para compreender a construção de significados. Ijuí, RS: Editora Unijuí, 2008.

LEME, M. I. da S. Jerome Bruner: o ensino e suas formas. In: REGO, T. C.(org.) Cultura, Aprendizagem e Desenvo/vimento. Petrópolis: Vozes; São Paulo: Editora Segmentos, 2011. p. 31-60.

LIMA, I. G. de; GANDIN, L. A. Estado, gerencialismo e políticas educacionais: construindo um referencial teórico de análise. 34ª Reunião Anual da ANPED. Natal, 2011. Disponível em: http://www.anped.org.br/app/webroot/34reuniao/.../GT05-667\%20int.pdf Acesso em: 02 nov. 2012.

MAINARDES, J. Abordagem do ciclo de políticas: uma contribuição para análise de políticas educacionais. Educação e Sociedade, Campinas, v. 27, n. 94, p. 47-69, jan./abr. 2006. Disponível em: http://www.cedes.unicamp.br. Acessado em: 01 de nov. de 2012

MAINARDES, J. Análise de políticas educacionais: breves considerações teórico-metodológicas. Contrapontos. v. 9, nº 1. p. 4-16. Itajaí, jan/abr 2009.

MARTINES, E. A. L. M. Estudo de Caso da Implantação do PROJETO UCA em Rondônia. UNIR: Porto Velho, 2011. (Aprovado pelo CNPq em setembro 2011).

MARTINS, L. M. A natureza histórico-social da personalidade. Cadernos CEDES, vol. 24, n. 62, 2004. p. 82-99. http://dx.doi.org/10.1590/S0101-32622004000100006. 
MORAN, J. M; MASETTO, M. T; BEHRENS, M. A. Novas tecnologias e mediação pedagógica. Campinas, SP: Papirus, 2009.

SANTOS, B. S. Os processos da globalização. 2002. Disponível em: http://www.eurozine.com/articles/2002-08-22-santos-pt.html Acesso em: 02 nov. 2012.

SOUZA, M. P. Psicologia Escolar e Políticas Públicas em Educação: Desafios Contemporâneos. Em Aberto. Brasília, v. 23, n.83 p. 129-149, março de 2010. Disponível em: http://www.rbep.inep.gov.br/index.php/emaberto/article/view/163/1303. Acesso em 20 nov. 2012. 